OPEN ACCESS

Edited by:

David J. Heldebrant,

Pacific Northwest

National Laboratory, United States

Reviewed by:

Eduardo Perez Gonzalez,

Universidade Estadual Paulista

Júlio Mesquita Filho, Brazil

Aaron Esser-Kahn,

University of California at Irvine,

United States

Julia Van Heek

RWTH Aachen University, Germany

*Correspondence:

Christopher R. Jones

c.r.jones@sheffield.ac.uk

Specialty section:

This article was submitted to Carbon

Capture, Storage, and Utilization,

a section of the journal

Frontiers in Energy Research

Received: 28 February 2017

Accepted: 11 May 2017

Published: 09 June 2017

Citation:

Jones CR, Olfe-Kräutlein B, Naims H and Armstrong K (2017) The Social

Acceptance of Carbon Dioxide

Utilisation: A Review

and Research Agenda.

Front. Energy Res. 5:11.

doi: 10.3389/fenrg.2017.00011

\section{The Social Acceptance of Carbon Dioxide Utilisation: A Review and Research Agenda}

\author{
Christopher R. Jones ${ }^{1,2 *}$, Barbara Olfe-Kräutlein ${ }^{3}$, Henriette Naims ${ }^{3}$ and Katy Armstrong ${ }^{1}$ \\ ${ }^{1}$ UK Centre for Carbon Dioxide Utilisation (CDUUK), University of Sheffield, Sheffield, United Kingdom, \\ ${ }^{2}$ Environment and Behaviour Research Group (EBRG), Department of Psychology, University of Sheffield, Sheffield, \\ United Kingdom, ${ }^{3}$ Institute for Advanced Sustainability Studies (IASS), Potsdam, Germany
}

$\mathrm{CO}_{2}$ utilisation technologies - also called carbon dioxide utilisation (CDU) and carbon capture and utilisation (CCU)-convert $\mathrm{CO}_{2}$ via physical, chemical, or biological processes into carbon-based products. $\mathrm{CO}_{2}$ utilisation technologies are viewed as a means of helping to address climate change and broadening the raw material base for commodities that can be sold to generate economic revenue. However, while technical research and development into the feasibility of $\mathrm{CO}_{2}$ utilisation options are accelerating rapidly; at present, there has been limited research into the social acceptance of the technology and $\mathrm{CO}_{2}$-derived products. This review article outlines and explores three key dimensions of social acceptance (i.e., socio-political, market, and community acceptance) pertaining to innovation within $\mathrm{CO}_{2}$ utilisation. The article highlights the importance of considering issues of social acceptance as an aspect of the research, development, demonstration, and deployment process for $\mathrm{CO}_{2}$ utilisation and explores how key stakeholders operating on each dimension might affect the innovation pathways, investment, and siting decisions relating to $\mathrm{CO}_{2}$ utilisation facilities and $\mathrm{CO}_{2}$-derived products. Beyond providing a state-of-the-art review of current research into the social acceptance of $\mathrm{CO}_{2}$ utilisation, this article also outlines an agenda for future research in the field.

Keywords: carbon dioxide utilisation, carbon capture and utilisation, social acceptance, public perception, review

\section{INTRODUCTION}

Carbon dioxide utilisation $\left(\mathrm{CO}_{2}\right.$ utilisation or $\left.\mathrm{CDU}\right)$ technologies-also called Carbon Capture and Utilisation (CCU) technologies-utilise $\mathrm{CO}_{2}$ as a valuable carbon resource. $\mathrm{CO}_{2}$ utilisation technologies can be defined as converting $\mathrm{CO}_{2}$ via physical, chemical, or biological processes into carbon-based products (see Figure 1). Thus, these technologies can be thought of as a new synthetic carbon cycle, which uses and releases $\mathrm{CO}_{2}$ back to the atmosphere or sequesters it in products. By sequestering $\mathrm{CO}_{2}$ and/or reducing the direct reliance on extracted fossil fuels as a carbon-feedstock for the manufacture of commodity products, $\mathrm{CO}_{2}$ utilisation technologies are seen as a means of helping to mitigate climate change, while simultaneously creating useful, saleable products that can potentially offset the costs associated with the capture and/conversion processes (Styring et al., 2014).

$\mathrm{CO}_{2}$ utilisation is often directly compared and contrasted with Carbon Capture and Storage (CCS); however, they are two distinct technology paths and so it is necessary to treat and evaluate these technologies individually, especially with regard to environmental policy targets (Bruhn et al., 2016). Specifically, CCS is a $\mathrm{CO}_{2}$ mitigation strategy; its objective is to deal with large volumes of $\mathrm{CO}_{2}$ 


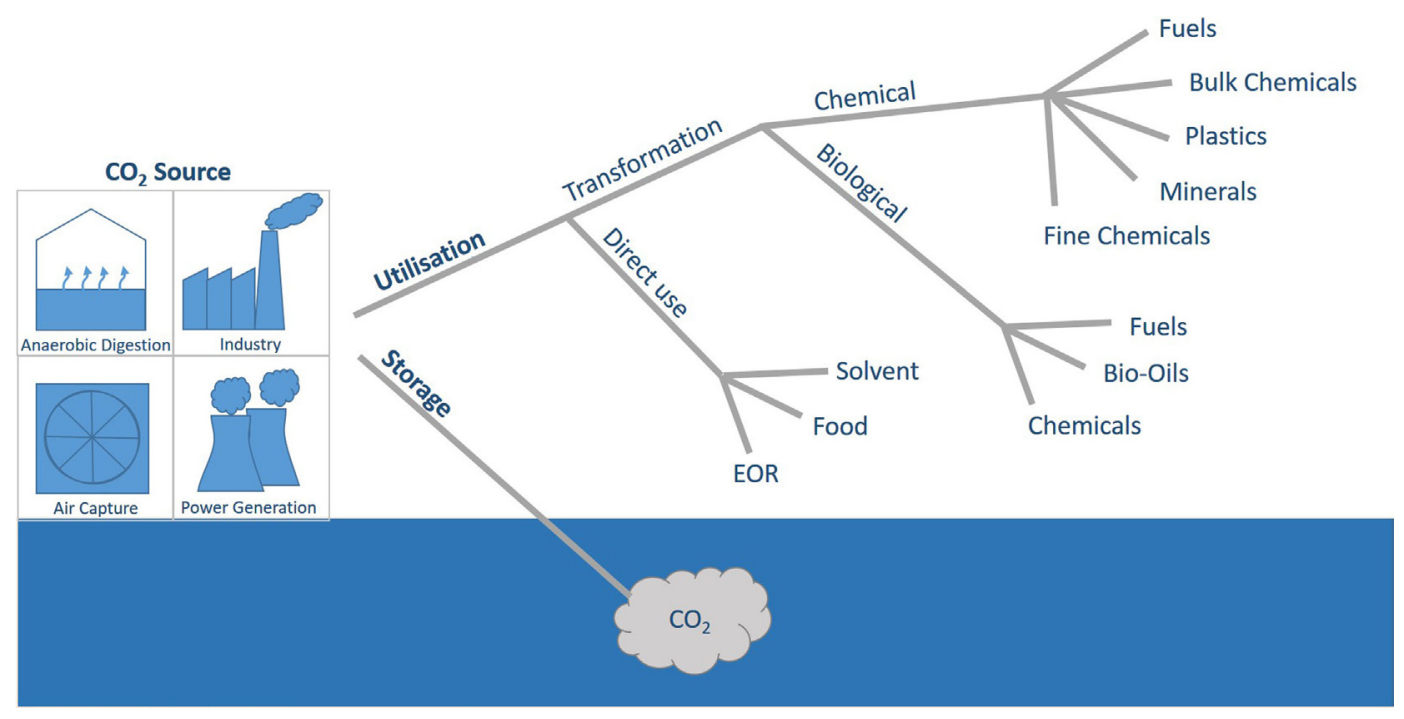

FIGURE 1 | Carbon dioxide storage and utilisation options. Carbon dioxide from point source emitters (e.g., fossil fuel power generation or other large industrial emitters) or via direct air capture or biological processes can be geologically stored (via carbon capture and storage) or used. Use of $\mathrm{CO}_{2}$ can be direct (e.g., for use in "enhanced oil recovery") or the captured $\mathrm{CO}_{2}$ can be transformed via chemical or biological processes for use as a carbon feedstock (e.g., for the manufacture of fuels, chemicals, plastics, etc.).

emissions by capturing and sequestering the gas in geological formations for periods of hundreds of years (Intergovernmental Panel on Climate Change, 2005). $\mathrm{CO}_{2}$ utilisation on the other hand uses $\mathrm{CO}_{2}$ as a feedstock for the creation of new, value-add products; it can promote sustainability and a circular economy, encourage industrial symbiosis and economic growth and enable the storage of renewable energy. Thus, while both technologies "capture" $\mathrm{CO}_{2}$, the subsequent treatment of the gas is very different.

While the majority of $\mathrm{CO}_{2}$ utilisation options remain at low technology readiness levels (or TRLs) (Wilson et al., 2015), some $\mathrm{CO}_{2}$-derived products are beginning to emerge on to the market [e.g., synthetic methane (or "e-gas") produced by Audi; polyols manufactured by Covestro and Novomer (under the trade names Cardyon and Converge, respectively) and construction aggregates from the accelerated mineralisation of waste ashes by Carbon8 Aggregates]. Importantly, as the commercialization of products and processes continues, there will be an associated growth in the interactions that a diversity of social stakeholders (including policymakers, businesses, the general public, etc.) will share with $\mathrm{CO}_{2}$ utilisation facilities and products. For example, consumer purchase decisions may help to determine whether products containing $\mathrm{CO}_{2}$ succeed in a competitive marketplace. Thus, developing a firm understanding of the factors and actors likely to shape the "social acceptance" of $\mathrm{CO}_{2}$ utilisation should be a priority for research. Interestingly, however, to date there has been very little systematic research in this area (Jones et al., 2015). This is a situation that contrasts markedly with the rich literature that now exists relating to the key factors and actors likely to govern the "social acceptance" of CCS technologies (see, e.g., L'Orange Seigo et al., 2014).

Within the current article, we directly address this knowledge gap by first outlining a key framework for conceptualizing the social acceptance of technological innovation, before summarizing and synthesising the findings from the extant literature pertaining to the social acceptance of $\mathrm{CO}_{2}$ utilisation technologies. Where relevant, inferences about the factors and actors likely to shape the future commercial success of $\mathrm{CO}_{2}$ utilisation are also made. We end by outlining a research agenda for future academic inquiry into the social acceptance of $\mathrm{CO}_{2}$ utilisation technologies; highlighting the key questions that need addressing and the methodological considerations that should be kept in mind in the pursuit of such research.

\section{THE IMPORTANCE OF SOCIAL ACCEPTANCE}

Social acceptance, or the extent to which an innovation (e.g., a policy, technology) is endorsed or rejected by key social actors (e.g., politicians, financiers, and publics), is recognised as being necessary for the successful introduction and commercial success of such innovation (e.g., Wüstenhagen et al., 2007; Perlaviciute and Steg, 2014; Upham et al., 2015). This is particularly the case within Western democracies, where policy or institutional change typically requires the support of individuals and communities (Peterson et al., 2015). Indeed, there are a growing number of examples of where failures to appropriately engage with, assess and accommodate the opinions of key social actors at a general, regional and/or local level has led to delays or curtailments to the introduction of innovations (e.g., GM technology, Horlick-Jones et al., 2006; renewable energy technologies, Devine-Wright, 2011).

Formal investigations into the social acceptance of new technologies date back to the 1980s where, at the time, a growing recognition of the governing influence that myriad stakeholders could exert upon the path of technological innovation, 
investment, and deployment led to a realisation that understanding (and influencing) the factors affecting the success of such innovation demanded more than a simple assessment of general public opinion (Wüstenhagen et al., 2007; Fournis and Fortin, 2017). Since then, respect for the importance of understanding and addressing the issue of social acceptance (and social acceptability $^{1}$ ) of technologies has grown rapidly (Fournis and Fortin, 2017).

Logically, a diversity of frameworks of social acceptance have followed-stemming from a number of psychological, sociological, and technical perspectives-aiming to provided working definitions of "acceptance" and showcase the important dimensions and stakeholders (and their associated relationships) that underpin whether or not technological or policy innovations are accepted (e.g., Szarka, 2007; Wüstenhagen et al., 2007; Shove, 2010; Huijts et al., 2012; Upham et al., 2015).

For example, Huijts and colleagues (2012), from a psychological perspective, propose a comprehensive framework of public acceptance of sustainable energy technologies (SETs). This framework considers an individual's intentions to support or oppose SETs to be a product of their attitudes, personal norms, perceived behavioural control, and subjective norms; concepts which are in turn predicted by other factors (e.g., perceived costs, risks, and benefits of the SET). However, while Huijts et al.'s (Huijts et al., 2012) framework provides a helpful take on the issues of public acceptance (see also Gupta et al., 2012), it fails to acknowledge that the social acceptance of innovation is governed by manifold social stakeholders (including but not limited to publics) working at multiple levels (macro, meso, and micro). Furthermore, the model cannot accommodate the epistemological differences of research stemming from other disciplinary perspectives (e.g., sociological accounts of technology acceptance, e.g., Shove, 2010).

With this in mind, the introduction to the social acceptance of $\mathrm{CO}_{2}$ utilisation within the current article is structured in accordance with Wüstenhagen et al.s (Wüstenhagen et al., 2007) "triangle of social acceptance" (see also Wolsink, 2012); a broader, conceptual framework, which characterizes the three levels of acceptance typically thought to shape the fate of technological and policy innovation (Upham et al., 2015). According to this framework, social acceptance of innovation to be the product of three dimensions: socio-political, market, and community acceptance (see Figure 2). While originally designed to profile the factors and actors influencing the social acceptance of renewable energy policy and technologies; the "triangle" framework has been applied within other policy domains, such as waste management and climate change adaptation (Wolsink, 2010).

According to Wüstenhagen and colleagues (2007), sociopolitical acceptance refers to the acceptance of technologies

\footnotetext{
${ }^{1}$ There is ambiguity around the use of the terms "acceptance" and "acceptability." While often used interchangeably they are noted to be different concepts (Fournis and Fortin, 2017). We favour use the term "acceptance" within the current article, not only because it is used by the "triangle" framework (i.e. the conceptual framework around which we structure the current review) but it is also a term that simplistically refers to whether something is accepted or not, as opposed to mapping to more complex, dynamic and hierarchical discussions of collective choice (Szarka, 2007).
}

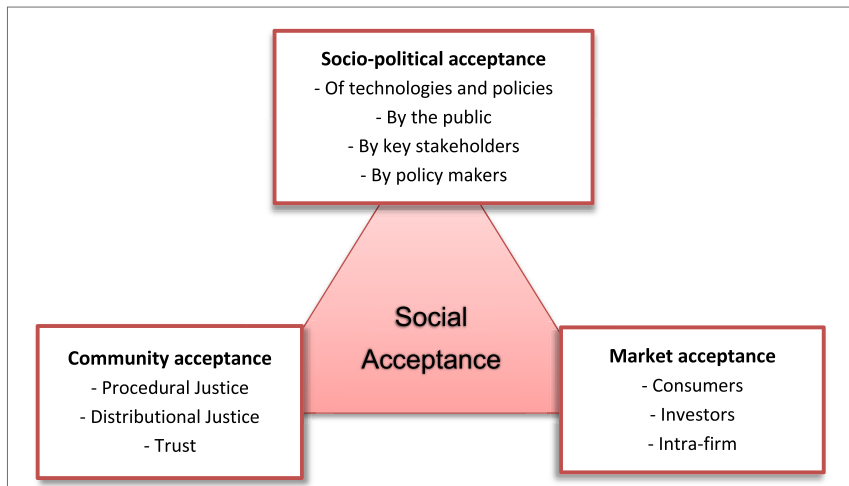

FIGURE 2 | The "Triangle of Social Acceptance." The "triangle" framework proposes that the social acceptance of policy and technology innovation is determined by the opinions and actions of stakeholders operating on three dimensions (i.e., socio-political, market, and community acceptance). The figure is adapted from Wüstenhagen et al. (2007) and is reproduced with the permission of the copyright holder.

and policies at the broadest, most general level by major social actors (e.g., the general public, policy-makers). By contrast, market acceptance is more specific and integrates considerations of the diffusion of innovation among consumers and the interactions and investment decisions of technology investors (e.g., the chemical industry or plant engineers); operating as both competitive and collaborative entities within both national and/ or multinational contexts. Finally, community acceptance is the acceptance of specific projects at a local level by stakeholders (particularly residents and local authorities) living proximal to the development. It is at this level that trust in decision-makers and perceptions of procedural and distributive justice (i.e., the extent to which decision-making processes and the distribution of risk and benefits are thought to be fair and equitable) are believed to shape the ability to deploy specified projects.

According to the "triangle" framework, the three dimensions of social acceptance are often interrelated (i.e., the decisions made by key actors on one dimension can have ramifications for acceptance of innovation on the other dimensions). For example, failures to institutionalize frameworks to promote market and community acceptance at the socio-political level (e.g., procurement mechanisms, decision-making protocols) can mean that general support for a technology may fail to translate into business and consumer investment and/or local support for the construction of specified projects. Similarly, it is possible that existing market path-dependencies can provide inertia to the adoption of technological innovations endorsed at a socio-political and/ or community level. Further, it is the differences in acceptance recorded at the socio-political (i.e., general) and community (i.e., local) level that has given rise to extensive research into so-called NIMBYism (not in my backyard, e.g., van der Horst, 2007; Jones and Eiser, 2010) and ongoing debates around the benefits and drawbacks of devolved versus centralised decision making (e.g., Bouffard and Kirschen, 2008).

While some researchers have critiqued the general concept of "social acceptance" (e.g., Batel et al., 2013) or have criticized Wüstenhagen et al's framework for failing to fully and explicitly 
define the assumptions upon which it rests and/or recognize the complexities around the stakeholder relationships it identifies (Fournis and Fortin, 2017); the "triangle" framework is widely cited and provides a good basis from which to foster a global understanding of the people and processes that are likely to determine whether or not innovations are socially accepted and therefore succeed or fail. Moreover, the proposed key dimensions of acceptance (i.e., socio-political, community, and market acceptance) have been confirmed by other commentators (e.g., Upham et al., 2015).

In the following sections, then, we explore each of the three dimensions of the "triangle" in turn; outlining the factors and actors that are likely to influence decisions about the acceptance of $\mathrm{CO}_{2}$ utilisation (both in general and with regard to specific products or siting of facilities) and summarising the nature and findings of any extant research that has been conducted. The review ends by proposing a number of key research questions that we feel should form the basis of future investigation in the field.

\section{THE SOCIAL ACCEPTANCE OF $\mathrm{CO}_{2}$ UTILISATION}

\section{Socio-Political Acceptance}

General socio-political support for (or rejection of) a given innovation can fundamentally shape its success. There are numerous examples of where failures to secure appropriate socio-political support for a technology has delayed or curtailed its introduction. This is exemplified, for example, by resistance to the introduction of E10 ( $10 \%$ ethanol) automotive fuel in a number of countries due to concerns about its effect on fuel prices and the perceived risks it poses to the operation of some older vehicles (Hauke, 2014). Also, the introduction of CCS technologies in some countries (e.g., Germany) has been stymied by a strong resistance to the concept among stakeholders and the general public (Brunsting et al., 2011; L'Orange Seigo et al., 2014). The following section outlines some of the key factors and actors at the socio-political level that are likely to shape the development and deployment of $\mathrm{CO}_{2}$ utilisation technologies.

The primary driver behind socio-political interest in $\mathrm{CO}_{2}$ utilisation to date has been climate change mitigation. This interest has arisen in response to national and international legislation regarding greenhouse gas emissions (e.g., European Union Emission Trading System, the Renewable Energy Directive, and the Fuel Quality Directive). Policy-makers are concerned with reducing the "carbon footprint" of their individual countries and industrial emitters are concerned with the possibility of economic penalties that could result from their emissions. These growing pressures (alongside other concerns, e.g., ensuring the security of raw resources) have led to accelerated innovation in technology and policy relating to $\mathrm{CO}_{2}$ utilisation.

Within this space, one can assume that the views of societal opinion leaders and industrial-sector decision-makers about whether or not to invest in $\mathrm{CO}_{2}$ utilisation (or particular technology or product options) - shaped by, for example, individual expertise, personal opinions, "bottom line" considerations, policy support, and media coverage (e.g., Kepplinger, 2007)—will influence the broader socio-political acceptance of $\mathrm{CO}_{2}$ utilisation and, hence, investment and development of the technology. However, while there have been informal efforts to engage with and network interested actors (e.g., by SCOT and CO2Chem $)^{2,3}$ to date there has been no formal systematic research in this area. As such, we argue that formal stakeholder analysis (e.g., Hemmati, 2002; Roloff, 2008; Freeman, 2010) in order to identify the key industrial (and other) stakeholders within the sector (both emitters and users) and to establish their motivations and requirements for investment should be a priority. This will identify levers, synergies, and courses of action which can be undertaken from both a policy and industrial perspective.

Public funding schemes and research-programme investment are a key means by which synergies can be formed and innovation encouraged. They provide a high level of facilitation for innovative technologies and, in turn, can positively steer internal decision making processes. There are currently around 34 governmental programmes for research into $\mathrm{CO}_{2}$ utilisation worldwide. ${ }^{4}$ The pre-requisites for the establishment of such programmes are manifold but appear to include, for instance, the existence of a strong chemical industry (e.g., Germany, Netherlands, Korea), the existence of an extractive oil or gas industry that has an interest in "enhanced recovery" applications (e.g., Canada, USA), or, in countries that plan to continue to use fossil fuel resources for their energy supply, the existence of coal-fired plants aiming at installing "Clean Coal" systems (e.g., China) (Olfe-Kräutlein et al., 2016, for a full outline of current programmes).

Interestingly, there often appears to be a disjunction between what developers see as the primary purpose of $\mathrm{CO}_{2}$ utilisation technology and the motivations driving governmental researchprogramme investment in the sector. That is, while industrial and academic actors involved in the development of $\mathrm{CO}_{2}$ utilisation technologies emphasise the fairly limited contribution that such technologies can make to climate change mitigation efforts (e.g., due to a dependency on the availability of renewable energy, see e.g., Bringezu, 2014); research programme investment is often rooted in this "climate change mitigation" context. There are evident questions as to the long-term consequences that any difference in the purported versus perceived rationale for $\mathrm{CO}_{2}$ utilisation might have for future public investment in the sector. Arguably, policies for investment need to evolve and realign to recognise the wider use-value of $\mathrm{CO}_{2}$ utilisation technologies (e.g., contributions to the sustainability and breadth of the raw material base of a country); this is something which has been recognised by the German government through their $\mathrm{CO}_{2} \mathrm{Plus}$ initiative (funded as part of the broader "Green Economy" initiative).$^{5}$

Relatedly, there are questions as to how wider socio-political confidence in $\mathrm{CO}_{2}$ utilisation might be affected by any misalignment in the perceived versus stated rationales for investment in the technology. For example, the way in which $\mathrm{CO}_{2}$ utilisation is

\footnotetext{
${ }^{2}$ http://www.scotproject.org/

${ }^{3}$ http://co2chem.co.uk/

${ }^{4} \mathrm{http}: / /$ database.scotproject.org/

${ }^{5}$ https://www.ptj.de/co2plus
} 
publicly "framed" might have consequences for support among a number of socio-political actors including, notably, the general public. Indeed, not only does research into framing reveal how the manner in which technological innovation is presented can exert a large impact on public opinion (e.g., Chong and Druckman, 2007; Jones et al., 2012; de Vries et al., 2016) but also that perceived discrepancies between the purported and perceived rationale for investment in technology can negatively affect public trust (e.g., Terwel et al., 2011).

While the views of the general public are a known determinant of the success of technological and policy innovation; research into the public acceptance of $\mathrm{CO}_{2}$ utilisation is currently sparse. This reflects the early technology readiness level of many $\mathrm{CO}_{2}$ utilisation options and low level of public awareness of the technology at the present time. The few studies that do exist have tended to use discursive methods (e.g., focus groups, semi-structured interviews) to assess initial understanding of the technology and gain initial insights into the factors that might underpin acceptance (e.g., Jones et al., 2014, 2016; van Heek et al., 2017a,b). That said, recently, details of findings from larger scale surveys are beginning to emerge (Perdan et al., 2017). In combination with formative research into the opinions of selected experts (Olfe-Kräutlein et al., 2016; van Heek et al., 2017a,b) and via monitoring participation in stakeholder discourse events (Olfe-Kräutlein et al., 2016), a picture of public perceptions of $\mathrm{CO}_{2}$ utilisation technologies (and how these map to and/or diverge from those of experts) is beginning to build.

The results of these studies generally confirm that awareness of $\mathrm{CO}_{2}$ utilisation is currently very low and while there is some scepticism about the long-term environmental benefits of the technology, there is tentative overall support for the concept as a "bridging technology" in the fight against climate change (Jones et al., 2015, 2016). This support is, however, strongly caveated by people's self-professed lack of knowledge of the technology, questions over the techno-economic feasibility of the processes and uncertainty over the societal consequences of investment in the technology. For example, some people question whether or not investment in $\mathrm{CO}_{2}$ utilisation could detract from investment in more preferable low-carbon technologies (e.g., renewables) or conflict with broader sustainability goals (e.g., $\mathrm{CO}_{2}$ utilisation is seen by some as being predicated on the continued use of fossil fuels) (e.g., Jones et al., 2016). A summary of the formative research that has been conducted to date into general public perceptions of $\mathrm{CO}_{2}$ utilisation can be found in Table 1 .

To some extent, the results of this initial research into public perceptions can be seen to be a product of the pro-environmental focus of the framing used to introduce the technology to participants. The power that such framing is likely to have on opinions is likely to be further enhanced by the novelty and unfamiliarity of the technology (Druckman and Bolsen, 2011). An obvious starting point for future research in this area, then, is to investigate the role that different framing of $\mathrm{CO}_{2}$ utilisation (e.g., to focus on alternative costs, benefits, or risks) might have on public opinion. Moreover, there are related questions pertaining to how emerging mental models and/or affective evaluations of $\mathrm{CO}_{2}$ shape how communications regarding $\mathrm{CO}_{2}$ utilisation are perceived among lay-publics (e.g., Montijn-Dorgelo and Midden, 2008).
TABLE 1 | Summary of the key studies conducted into emerging perceptions of $\mathrm{CO}_{2}$ utilisation technologies and product options.

\begin{tabular}{|c|c|c|}
\hline Study (location) & Year & Aim \\
\hline $\begin{array}{l}\text { Jones et al. } \\
\text { (2014) (UK) }\end{array}$ & 2014 & $\begin{array}{l}\text { Qualitative focus group study with follow-up } \\
\text { information-choice questionnaire, designed } \\
\text { to (a) test a methodology for assessing public } \\
\text { perceptions of } \mathrm{CO}_{2} \text { utilisation and (b) elucidate } \\
\text { new understanding of people's attitudes to the } \\
\text { technology }\end{array}$ \\
\hline $\begin{array}{l}\text { Jones et al. } \\
\text { (2015) (UK) }\end{array}$ & 2015 & $\begin{array}{l}\text { Qualitative focus group study (with questionnaire), } \\
\text { building on } 2014 \text { study, designed to investigate } \\
\text { and assess emerging lay public perception of } \\
\mathrm{CO}_{2} \text { utilisation among groups of adults and high } \\
\text { school students }\end{array}$ \\
\hline $\begin{array}{l}\text { Olfe-Kräutlein et al. } \\
\text { (2016) (Germany) }\end{array}$ & 2016 & $\begin{array}{l}\text { Semi-structured interview and participant } \\
\text { observation study, designed to explore the } \\
\text { potential for and barriers to communication about } \\
\mathrm{CO}_{2} \text { utilisation. Study provides (a) an analysis of } \\
\text { expert and other stakeholder perspectives and (b) } \\
\text { strategic comments for future communications } \\
\text { regarding } \mathrm{CO}_{2} \text { utilisation }\end{array}$ \\
\hline $\begin{array}{l}\text { Jones et al. } \\
\text { (2016) (UK/Germany) }\end{array}$ & 2016 & $\begin{array}{l}\text { Focus group study (with questionnaire), designed } \\
\text { to investigate and compare and contrast } \\
\text { laypeople's opinions towards } \mathrm{CO}_{2} \text { utilisation } \\
\text { technologies in the UK and Germany }\end{array}$ \\
\hline $\begin{array}{l}\text { Arning et al. } \\
\text { (2017) (Germany) }\end{array}$ & 2017 & $\begin{array}{l}\text { Qualitative focus group and online survey study, } \\
\text { designed to (a) conceptualize } \mathrm{CO}_{2} \text {-utilisation risk } \\
\text { perception; (b) evaluate the relationship between } \\
\text { risk perception and product acceptance and } \\
\text { (c) provide a breakdown of the factors affecting } \\
\text { responses within different user-groups }\end{array}$ \\
\hline $\begin{array}{l}\text { van Heek et al. } \\
\text { (2017a) (Germany) }\end{array}$ & 2017 & $\begin{array}{l}\text { Qualitative interview study designed to assess } \\
\text { acceptance of different } \mathrm{CO}_{2} \text {-derived plastic } \\
\text { products. Study compares layperson and } \\
\text { scientific expert attitudes and perspectives }\end{array}$ \\
\hline $\begin{array}{l}\text { van Heek et al. } \\
\text { (2017b) (Germany) }\end{array}$ & 2017 & $\begin{array}{l}\text { Combination of qualitative and quantitative } \\
\text { methods with the aim to deliver insights into } \\
\text { acceptance drivers and barriers connected to } \\
\mathrm{CO}_{2} \text { utilisation technology }\end{array}$ \\
\hline $\begin{array}{l}\text { Perdan et al. } \\
(2017)(\mathrm{UK})\end{array}$ & 2017 & $\begin{array}{l}\text { Quantitative survey of } 1213 \text { UK adults, designed } \\
\text { to establish the extent of people's awareness } \\
\text { and acceptance of } \mathrm{CO}_{2} \text { utilisation and to elicit } \\
\text { the importance they put on different sustainability } \\
\text { issues relevant to the technology }\end{array}$ \\
\hline
\end{tabular}

Full references for the studies can be found in the reference section.

One of the mooted benefits of research into public perception is that the knowledge gleaned from such activity could be used in order to inform public engagement and communication materials by helping to identify possible misperceptions and/or key concerns and benefits. Parallel research conducted into public perceptions of carbon capture and storage (CCS), for example, has been used to provide a scientifically sound basis for communication relating to this technology (Brunsting et al., 2011). Intriguingly, early evidence shows that the conceptual relatedness of CCS to $\mathrm{CO}_{2}$ utilisation (and the fact it is often called CCU) could have implications for the public acceptance of $\mathrm{CO}_{2}$ utilisation technology (Jones et al., 2016), particularly in countries or contexts where CCS has proven to be controversial and/or rejected at a socio-political level (e.g., Germany) (L’Orange Seigo et al., 2014).

A key shaper of public opinion at the socio-political level is the media. Media coverage (e.g., news reports) continues to 
play an important role in spreading information and raising awareness about technological innovation (Hampel and Zwick, 2016; Weitze and Weingart, 2016). While a full analysis of media coverage of $\mathrm{CO}_{2}$ utilisation technologies has yet to be published (and remains a priority for future research), informal analysis indicates that media coverage at present tends to be positive. Although, negative connotations have been reported in some contexts where $\mathrm{CO}_{2}$ utilisation is considered alongside CCS technologies (Bruhn et al., 2016). A number of interesting questions exist regarding how media coverage will develop and shape public opinion going forward. For example, there are questions as to whether or not media exaggeration of the purported benefits of $\mathrm{CO}_{2}$ utilisation might raise false expectations among the general public and other socio-political stakeholders (Olfe-Kräutlein et al., 2016).

In summary, how technological innovation is received and responded to at the socio-political level has key implications for investment decisions and public support. The studies that have been conducted to date have provided first insight into some of the factors likely to govern acceptance at a socio-political level. These indicators should now serve as a starting point for more comprehensive research in the field. An option for such research-and one that would allow for a wider precis of the key non-technical factors and actors likely to foster acceptance or rejection of $\mathrm{CO}_{2}$ utilisation at this level-is to use a multistakeholder approach (e.g., Freeman, 2004, 2010). This approach would allow for a wider and more diverse group of stakeholders to participate in the dialogue about the future of $\mathrm{CO}_{2}$ utilisation; as well as helping to highlight the dynamics of decision making regarding acceptance at the socio-political level.

\section{Market Acceptance}

Wüstenhagen et al. (2007), p. 2685 define market acceptance as "...the process of market adoption of an innovation" and examine it in regard to acceptance among consumers, investors, and intrafirm actors. In this market perspective, the decision to accept or reject an innovation is based on diffusion theory (Rogers, 1995). Diffusion theory separates the uptake of innovation into five steps: (1) knowledge, (2) persuasion, (3) decision, (4) implementation, and (5) confirmation (see Figure 3). The success of diffusion is assessed as "the number of individuals who adopt a new idea in a specified period" (Rogers, 1995, p. 206). This measure is influenced by a variety of factors, including the perceived attributes of the innovation, the type of innovation decision and the communication channels available (Rogers, 1995). Consequently, for any group of market actors (consumers, investors, and intra-firm actors) these factors should be considered to better understand the adoption process steps and the resulting acceptance or rejection of an innovation. In the following section, we use diffusion theory as a lens to explore the factors that might affect the market acceptance of $\mathrm{CO}_{2}$ utilisation technologies among consumers, investors, and intra-firm actors.

\section{Consumers}

To date, limited studies have focused specifically on consumer acceptance of $\mathrm{CO}_{2}$-derived products. The current exceptions

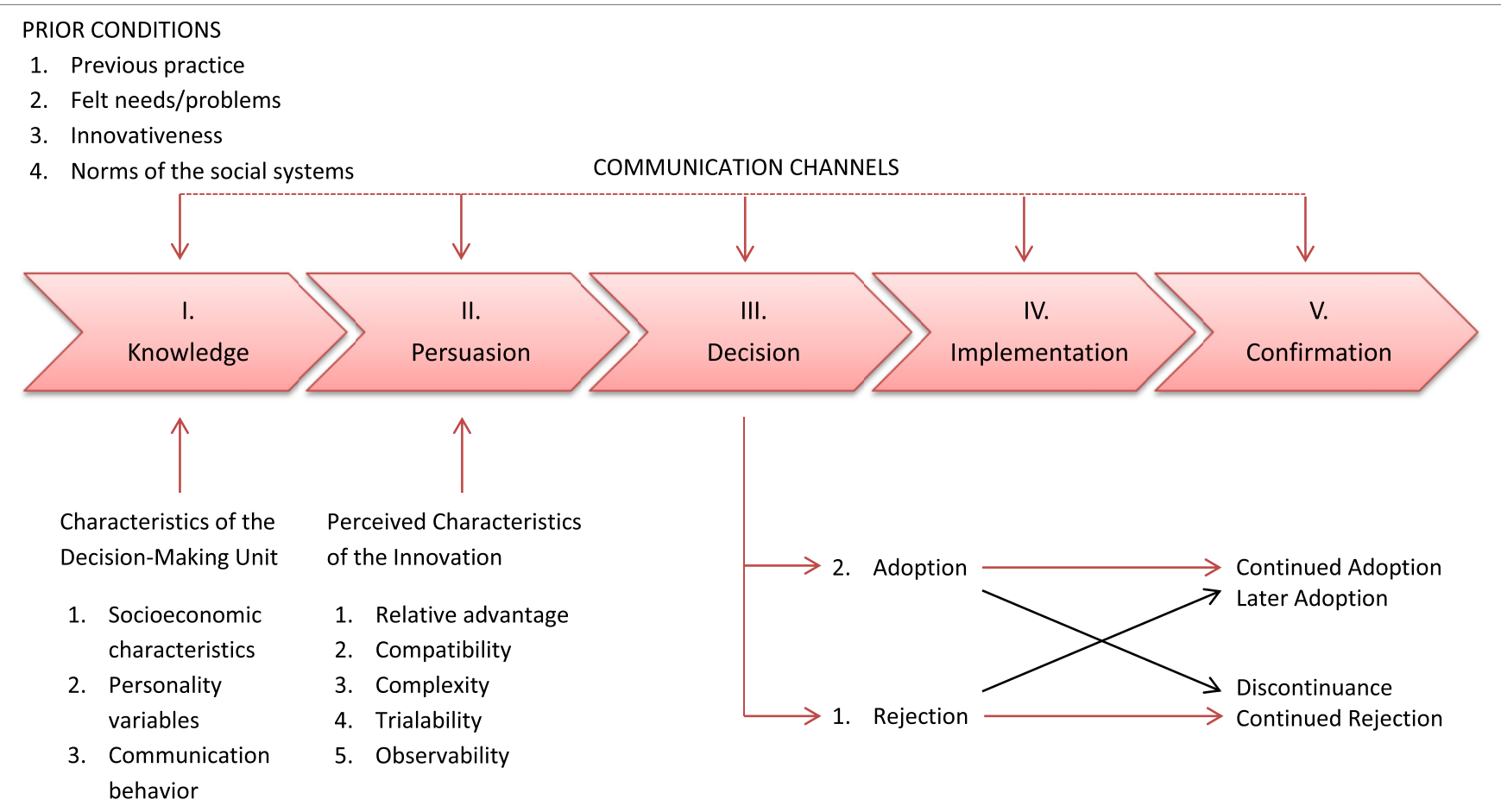

FIGURE 3 | A model of stages in the innovation-decision process. According to the model, adoption or rejection of innovation proceeds through five consecutive stages. Source: Rogers (1995), p. 165. This is an adapted version of the original figure that is reproduced with the permission of the copyright holder. 
include two small qualitative studies that have focused on assessing potential consumer perceptions of $\mathrm{CO}_{2}$-derived mattresses and plastics (Arning et al., 2017; van Heek et al., 2017a,b). Both studies reveal that the risk is deemed to be relatively low and that people tend to have positive perceptions of the products. However, while these findings are encouraging for proponents of $\mathrm{CO}_{2}$ utilisation (e.g., investors); as both studies asked people to consider the purchase of hypothetical (rather than actual) products, there are limitations to the conclusions that can be derived regarding actual real-world consumer acceptance. As more "real" $\mathrm{CO}_{2}$-derived consumer products reach the marketplace, it will be possible to analyse the specific effects of how, for instance, advertising, product pricing, and labelling will affect purchasing behaviour. Presently, though, learning more about the processes by which consumer opinions are liable to be formed and shaped-particularly prior to the decision to adopt or reject an innovation-is essential.

In most cases, materials derived from $\mathrm{CO}_{2}$ utilisation will be retailed to intermediaries (e.g., product manufacturers or distributers) rather than directly to end-consumers. It is currently unclear to what extent the final retailers of consumer goods will seek to label their products as being " $\mathrm{CO}_{2}$-derived" or with other possible messages in attempt to gain competitive market advantage (Olfe-Kräutlein et al., 2016). While there are open questions as to whether certain consumers will accept or reject $\mathrm{CO}_{2}$-derived products on principle (e.g., irrespective of labelling or advertising); there are particularly interesting questions relating to how end users will respond in those cases where products are explicitly marketed as $\mathrm{CO}_{2}$ derived. It is in these cases where the opinions of consumers will exert a particularly strong influence on the ultimate success or failure of the product(s) in question.

According to diffusion theory, because few $\mathrm{CO}_{2}$-derived products are available to consumers on the open market and so limited numbers of consumers have ever had to face the explicit decision for or against buying a $\mathrm{CO}_{2}$-derived product; the majority of end consumers can be considered as either having no exposure to such products or, at most, as being early in the knowledge stage of the model.

Perception of an innovation at the knowledge stage is shaped strongly by the characteristics of the socioeconomic system the consumers are part of, the communication behaviours relating to the innovation and consumers' individual attitudes (see Figure 3). While learning of the existence of an innovation can provide a basis for its later adoption; whether or not consumers develop this knowledge is strongly shaped by their values, beliefs, and attitudes (Rogers, 1995). For instance, consumers are more likely to seek out information on $\mathrm{CO}_{2}$-derived products if such products are deemed to gel with their extant belief systems (e.g., if such products are seen as being congruent with their aspirations to live more sustainably).

At present, there are questions regarding the adequacy of the information that is available to consumers regarding $\mathrm{CO}_{2}$ utilisation (and more specifically $\mathrm{CO}_{2}$-derived products) in order to develop an informed understanding at the knowledge stage. Much of the information on the nature of $\mathrm{CO}_{2}$ utilisation (e.g., its consequences, advantages, disadvantages) remains in scientific publications that are inaccessible to most consumers. Moreover, while all companies distribute communication materials to their own customers, the current efforts largely target at business customers since most $\mathrm{CO}_{2}$-derived products are intermediates. The research community is thus increasingly aware of a need for neutral and evidence-based communication about $\mathrm{CO}_{2}$ utilisation innovations for a broader public; information that is aimed at improving the base knowledge of potential future consumers-for some existing examples, see Olfe-Kräutlein et al. (2014) and Krämer et al. (2015).

Once knowledge of an innovation has developed, the persuasion stage of Rogers's (Rogers, 1995) model becomes relevant. Whether or not efforts to persuade people regarding an innovation translates to the decision to adopt (or reject) it is strongly influenced by the communicated characteristics of the innovation, e.g., the relative advantage the innovation will afford consumers (i.e., how useful it will be) and the perceived compatibility of the innovation with existing lifestyle practices (see Figure 3). ${ }^{6}$ The decision over how $\mathrm{CO}_{2}$-derived products are promoted to consumers ultimately rests with the producers and/ or retailers consumer goods. As such, their marketing decisions about which product characteristics are emphasised will strongly influence how a product is received and whether or not it is later adopted or rejected.

\section{Investors}

In the context of $\mathrm{CO}_{2}$ utilisation, investors include public and private $\mathrm{R} \& \mathrm{D}$ funding programs (aiming to promote the general development and implementation of the technologies) and private companies that see a need to capture and/or use $\mathrm{CO}_{2}$ (e.g., large $\mathrm{CO}_{2}$ emitters, the chemical industry). In contrast to end-consumers, investors are currently significant market actors; however, decision making at the level of investors is usually a confidential and non-public process. While the knowledge stage in investment decision making is generally professionalised, it is nevertheless influenced by the characteristics of the decision making unit (e.g., a profit-focused hedge fund will set different preferences than a welfare-oriented public investor.) Whether an investor is then persuaded to invest in $\mathrm{CO}_{2}$ utilisation is likely to be rationally driven by strategic motives (such as the optimisation of profits or other desired KPIs) and, hence, progression through the latter stages of the diffusion model (decision, implementation, and confirmation) will depend largely on the defined targets and measurable outcomes of the investment.

While information on specific investment decisions is likely to remain largely confidential, it is nevertheless recommended to conduct research into the factors and actors driving these investment decisions. There are a few studies focussed on start-up companies (e.g., Zimmerman and Kant, 2016) or public investments (e.g., Olfe-Kräutlein et al., 2016), but a more detailed and systematic analysis of acceptance issues among investors would be beneficial. There is a further need for research into future path dependencies, for example, relating to infrastructure decisions and interfaces with the socio-political system (e.g., relevant regulation and frameworks) in order to better understand and

${ }^{6}$ Similar constructs are recognised in other key models of technology acceptance (e.g. the Technology Acceptance Model, e.g. Venkatesh and Davis, 2000). 
improve investment security for investors. While formative studies that touch upon some of the issues pertinent to investment decisions have been published (e.g., Bringezu, 2014; Wilson et al., 2015; Naims, 2016; Piria et al., 2016), there is need to continuously review and update these according to the evolving expectations of investors and changing regulatory and policy environments.

Crucially, there is a role for the academic community in providing evidence-based support for investors in their process of decision making. These are studies that evaluate the potential and risk of different $\mathrm{CO}_{2}$ utilisation innovations from an ecologic, economic and/or societal perspective; providing insight into the suitability and acceptability of different technologies in various future scenarios. Helpfully, the first of such studies, which not only largely focus on the environmental aspects and life cycle assessment of $\mathrm{CO}_{2}$ utilization (e.g., Bennett et al., 2014; von der Assen and Bardow, 2014; von der Assen et al., 2016) but also with regard to the circular economy (e.g., Styring et al., 2011; Bringezu, 2014) and socioeconomic context (e.g., Naims, 2016; Olfe-Kräutlein et al., 2016) have now been published. However, as with the research into path dependencies, there will be a need for further and/or updated studies as new technologies and markets develop.

\section{Intra-Firm Actors}

Intra-firm actors are the individuals (e.g., developers, managers) or groups of individuals (e.g., departments, boards) within a company who will also play a major role with regard to acceptance and diffusion of $\mathrm{CO}_{2}$ utilisation technologies and products. Research indicates that firms with a proactive environmental strategy tend to be more likely to invest in R\&D, technology, and human resources to develop their capabilities, even in uncertain business environments (Aragón-Correa and Sharma, 2003). Thus, it can be assumed that environmentally proactive firms, in addition to those with a comfortable competitive position, are more likely to advance the development and introduction of $\mathrm{CO}_{2}$ utilisation in comparison to those with more tentative innovation strategies and/or a weaker market position.

Within organisations, so-called "change agents" play an integral role in shaping the path of innovation. Change agents act through all stages of the diffusion process; in the best cases outlining the need for and increasing knowledge of innovations, before promoting the favourable characteristics of an innovation and expediting decision-making processes (Rogers, 1995). Consequently, the abilities of individual change agents, alongside the support systems provided to them within firms and the firms willingness and/or ability to shift extant intra-firm path dependencies (e.g., Alänge et al., 1998), will play a crucial role for the acceptance and diffusion at the intra-firm level.

At the current time, the principal intra-firm change agents for innovation in $\mathrm{CO}_{2}$ utilisation are technically trained R\&D professionals, project managers and/or business development managers. Currently, very little is known about how these individuals are operating within firms to shape the agenda for $\mathrm{CO}_{2}$ utilisation and the development, use and/or marketing of $\mathrm{CO}_{2}$-derived products. For example, what barriers do they face to implementing their ideas and how successful are they in communicating the need for change to their managers?
In sum, a number of factors and actors stand to shape the market acceptance of $\mathrm{CO}_{2}$ utilisation technologies and/or $\mathrm{CO}_{2}$ derived products. While investors are already significant actors in this arena, the first studies into their role and behaviour are ongoing and so only speculative conclusions can be drawn as to the processes driving their decisions to invest. Furthermore, while intra-firm environments and actors (e.g., change agents) are known to shape the uptake and diffusion of innovation; first studies in this field are also ongoing. Further attempts to assess their role for the diffusion and intra-firm acceptance of $\mathrm{CO}_{2}$ utilisation will be useful. Also, formal investigations into the nature of decision making within firms seeking to invest in the $\mathrm{CO}_{2}$ utilisation sector remains a priority for future research.

Similarly, while there is emerging intelligence on consumer attitudes towards $\mathrm{CO}_{2}$-derived products, there are currently significant limitations to this research. To the extent that (a) there will be increased number of $\mathrm{CO}_{2}$-derived products available to consumers in the future and (b) efforts will be made to gain competitive market advantage by communicating the source of carbon within these products, there needs to be increased research focus on the antecedents of consumer acceptance.

\section{Community Acceptance}

"Community acceptance" refers to "...the specific acceptance of siting decisions and [...] projects by local stakeholders, particularly residents and local authorities" (Wüstenhagen et al., 2007, p. 2685). Thus, according to Wüstenhagen and colleagues (2007), this dimension is the most specific dimension of acceptance and refers to the rejection or acceptance of particular facilities or projects within geographically defined "host" communities (see also Sovacool and Ratan, 2012).

While one could choose to debate this relatively narrow definition of community-e.g., one could seek to define "community acceptance" more liberally so as to recognise that "non-local" stakeholders (e.g., global NGOs) and "communities of interest" can still exert influence over the fate of specific projects (Young, 1986; Walker and Devine-Wright, 2008)—it is certainly the case that the opposition or support received for specified projects at a local level is a key contributor to their success or failure (e.g., Devine-Wright, 2011).

Social scientific research has revealed a considerable amount about the factors likely to affect community acceptance of any array of (proposed) industrial and/or other facilities. This research has not only registered the differences that can (apparently) exist between the acceptance of facilities when considered at a general (i.e., socio-political) versus a local (i.e., community) level but has also provided key insight into the myriad explanations that can account for these differences (e.g., van der Horst, 2007; Jones and Eiser, 2010; Bell et al., 2013). This has included efforts to investigate how project acceptance might differ in different countries and cultures (e.g., Toke et al., 2008; Pietzner et al., 2011).

Taken together, it can be concluded on the basis of research conducted to date, that issues of "place" (including social, cultural, and technological characteristics) and "process" (i.e., engagement and decision-making practices) are of central importance when it comes to understanding how proposed projects or facilities are received and responded to at a local level. This is particularly 
the case within Westernised democracies, where "policy and institutional changes require support from both individuals and communities" (Peterson et al., 2015, p. 1).

\section{Community Acceptance of $\mathrm{CO}_{2}$ Utilisation Facilities}

While there is a rich literature charting community acceptance of a large number of locally unwanted land-uses (LULUs) (e.g., prisons, power plants, and mental hospitals) (Schively, 2007) relatively little (if any) published research has specifically investigated opinions towards the prospect of $\mathrm{CO}_{2}$ utilisation facilities. This is despite the fact that there are existing examples of commercial $\mathrm{CO}_{2}$ utilisation facilities currently in operation (e.g., the Carbon Recycling International "Vulcanol" production plant, Grindavik, Iceland; Carbon8 “accelerated carbonation” facility, Brandon, UK).

To the extent that $\mathrm{CO}_{2}$ utilisation facilities are affiliated with (and are hence sited alongside) existing industrial operations, one could anticipate that the likelihood of prohibitive local opposition forming to earmarked facilities could be very low. Indeed, for communities living adjacent to such sites, who are familiar with and/or reliant on the extant plant for employment, the prospect of additional operations (and opportunities) might be viewed quite positively (e.g., Van Der Pligt et al., 1986; Jones et al., 2015). It is, however, by no means guaranteed that the presence of extant development will mean that further development will be condoned. For example, concerns over fairness and distributive justice (i.e., the distribution of benefits and burdens) or failings in the inclusivity and/or transparency of the decisionmaking process, might also shape community level acceptance (e.g., Dobson, 1998; Jones et al., 2011; Ottinger, 2013). Moreover, as technologies, product options and their associated markets develop, diversify, and mature; there is an increased likelihood that more (and more diverse) communities will face the prospect of hosting $\mathrm{CO}_{2}$ utilisation facilities. This will likely bring much less "familiar" populations into direct contact with such facilities.

We argue that the impact that the attitudes and behaviours of prospective host communities can have on the fate of such facilities, necessitates bespoke research into the nature and determinants of community acceptance towards $\mathrm{CO}_{2}$ utilisation facilities.

\section{The Risks of Drawing Conclusions Based on CCS Research}

It would be relatively easy to draw speculative conclusions about likely community responses towards prospective $\mathrm{CO}_{2}$ utilisation facilities by accessing the rich literature on "local" CCS development (e.g., Oltra et al., 2012; L'Orange Seigo et al., 2014). However, while there is some logic to this enterprise-bearing in mind the similarity in the terms and the fact that CCS and $\mathrm{CO}_{2}$ utilisation facilities are both industrial plant designed to treat or "sequester" carbon dioxide-there is also good reason to be cautious due to the abovementioned differences in nature, scale, and intended purpose of these technologies (Bruhn et al., 2016). Moreover, where research has provided participants with the opportunity to consider their opinions of $\mathrm{CO}_{2}$ utilisation in comparison with CCS (e.g., Jones et al., 2015, 2016), there is evidence of a number of fundamental differences in the perceived risks, costs, and benefits, including at the level of individual facilities, of these technology options.

Crucially, the formative research into public perception that has been completed to date (e.g., Jones et al., 2015, 2016) suggests that it is the transportation and storage of carbon dioxide-as opposed to the capture and/or conversion processes per se-that appear to be of most concern to those interviewed. This concern would appear to principally stem from the anticipated risk of $\mathrm{CO}_{2}$ leakage, which is deemed to at the very least undermine the purpose of the technology or at worst to pose a direct risk of death or illness through contamination of drinking water, explosion and/or asphyxiation (e.g., L'Orange Seigo et al., 2014). While this research does reveal that people do see some risks with $\mathrm{CO}_{2}$ utilisation facilities (e.g., risks from chemicals, explosion, etc.); currently, it appears that such facilities are likely to be viewed as any other form of generic industrial facility. Thus, it would appear that community level objections to $\mathrm{CO}_{2}$ utilisation facilities are likely to be grounded in concerns over the prospect of local industrial development per se, as opposed to any bespoke risks posed by the $\mathrm{CO}_{2}$ utilisation facility. It appears as though this tempered risk perception stems from both a trust in operators to run the facilities safely, as well as the comparatively benign, confined, and controlled nature of the processes being proposed; perhaps offset further by the prospect of local economic benefits (e.g., new jobs) (Jones et al., 2015).

\section{Is the Current Indifference to $\mathrm{CO}_{2}$ Utilisation Facilities a Positive Sign?}

The relative indifference regarding the prospect of local development indicated in the studies conducted to date should not be taken to mean that it is guaranteed that there will be no opposition to local facilities. As previously outlined, local opinion towards actual development can differ from that registered when facilities are considered in a more general, abstract and/or hypothetical sense (e.g., Jones and Eiser, 2010; Devine-Wright, 2011; Bell et al., 2013). The fact that the research conducted to date has only focused on the opinions of general, unaffected publics is thus a weakness in making specific predictions about the likely acceptance or rejection of specific projects. Moreover, the findings that have been accrued to date are based upon the responses of a relatively illinformed public (i.e., people with a low awareness and knowledge of the technology). It is possible that as people learn more about benefits and drawbacks of $\mathrm{CO}_{2}$ utilisation and/or the prospect of local development becomes more real that "unexpected" local objections could arise (e.g., Bell et al., 2005, 2013).

Taken together, the extant research on LULUs indicates that developers and investors should pay close attention to matters of "place" and "process" (Peterson et al., 2015) when seeking to site facilities. $\mathrm{CO}_{2}$ utilisation facilities are not a special case in this regard. While there are certain "unique" features of such technologies that might particularly resonate with host communities (e.g., specific perceived risks and benefits), the need to be (a) cognisant and responsive to the specific features and demands of a place and its people; and (b) make decisions in a fair, inclusive, and (ideally) participatory way, is now customary advice for finding common ground with potential host communities (e.g., Beierle and Cayford, 2002; Manzo and Perkins, 2006). That 
said, bespoke research into the community level acceptance of $\mathrm{CO}_{2}$ utilisation facilities does not yet exist and this should be a priority for future research.

\section{SUGGESTED RESEARCH AGENDA}

In the context of $\mathrm{CO}_{2}$ utilisation, the factors and actors relating to each of the three dimensions of the triangle of social acceptance (i.e., socio-political, market, and community acceptance) raise a number of novel and interesting research questions. While many of these questions have been outlined in the preceding sections; the following research agenda pulls out some of the priorities for future research in this field. This is not intended to be an exhaustive list of research questions but rather an outline of a handful of important avenues for initial inquiry, which are based upon the themes identified within this review article.

\section{Socio-Political Acceptance}

Socio-political support among the general public and other stakeholders can fundamentally shape the successful introduction of products and/or deployment of $\mathrm{CO}_{2}$ utilisation facilities. As such, key $\mathrm{CO}_{2}$ utilisation stakeholders should be identified as targets for future research (e.g., industry decision-makers, national, and international policy-makers, publics, and the media), and systematic programmes of investigation should be conducted in order to gain deeper insight into the antecedents and consequences of acceptance at this level. This research should seek to recognise and chart regional differences in socio-political acceptance of $\mathrm{CO}_{2}$ utilisation.

Recommended studies relating to socio-political acceptance include

- A systematic, issue- and organisation-focussed stakeholder analysis in order to identify and clarify the range of stakeholders with connections to the development and deployment of $\mathrm{CO}_{2}$ utilisation technologies and products (in different regions), as well as the reasons for their interest and/or investment in $\mathrm{CO}_{2}$ utilisation at the socio-political level.

- A broader and more-detailed analysis of the international media coverage of $\mathrm{CO}_{2}$ utilisation in order to assess emerging perceptions of $\mathrm{CO}_{2}$ utilisation technologies (among the media and reported stakeholders) and how these are influencing the public agenda on $\mathrm{CO}_{2}$ utilisation.

- A systematic analysis of the broader political agenda regarding $\mathrm{CO}_{2}$ utilisation and how it might influence the investment in and the further research and development of technologies and products. This research should model different investment and development pathways in different policy and legislative scenarios.

\section{Market Acceptance}

A number of stakeholders will affect the market acceptance of $\mathrm{CO}_{2}$ utilisation technologies and products. Notably, these include market actors, whose decisions to invest in $\mathrm{CO}_{2}$ utilisation technologies and/or to produce, purchase, utilise, or retail $\mathrm{CO}_{2}$-derived products will significantly shape innovation within the sector. Also, as more $\mathrm{CO}_{2}$-derived products become available on global markets, the opinions, and choices of consumers will necessarily have an influence of growing importance.

Future research in the area of market acceptance should include

- Detailed identification of market-stakeholders and analysis of their perceptions of $\mathrm{CO}_{2}$-derived products (including end-consumers) as they become commercially available. This research should seek to compare and contrast preferences for different $\mathrm{CO}_{2}$-utilisation options and analyse how the preferences are formed, spread and how they affect choice among different consumer-groups.

- A more-detailed and systematic analysis of the acceptance and diffusion of different $\mathrm{CO}_{2}$ utilisation technologies and products among investors. Studies should specifically investigate how the socio-economic environment and extant path dependencies affect behaviour among different investors.

- Research into intra-firm perception, attitudes, acceptance, and diffusion of $\mathrm{CO}_{2}$ utilisation technologies and products. In particular, the role that "change agents" have in influencing intra-firm decision making is a relevant area for research.

\section{Community Acceptance}

Whether or not specific $\mathrm{CO}_{2}$ utilisation facilities are welcomed at a local level could have implications for the overall success of the concept. While inferences can be drawn from analogous technological innovation, we currently know little about the community-level acceptance of $\mathrm{CO}_{2}$ utilisation facilities and less about how opinions might evolve following construction and (successful or interrupted) operation. While some $\mathrm{CO}_{2}$ utilisation facilities do currently exist, it is only a matter of time before more (and more diverse) communities will be invited to host facilities, either in isolation or in association with other industrial developments (e.g., CCS projects).

Two key questions that should form the basis of systematic future research in this area are:

- To what extent is the relative agnosticism (or indifference) currently shown towards hypothetical $\mathrm{CO}_{2}$ utilisation facilities mirrored within communities actually hosting facilities and/ or facing actual development (i.e., to what extent is there a "social gap" in $\mathrm{CO}_{2}$ utilisation facility siting, see Bell et al., 2005, 2013)?

- Which of the many "place" and "process" factors identified as influencing local project acceptance (Peterson et al., 2015) are most important in shaping people's attitudes (and behavioural responses) to $\mathrm{CO}_{2}$ utilisation facility development? For example, how does the presence and reliance on extant industrial development in a community affect acceptance of $\mathrm{CO}_{2}$ utilisation facilities?

In addition to shedding light on the extant nature of more specific, "local" opinion towards $\mathrm{CO}_{2}$-utilisation facility development, the findings of such research hold the potential to help inform public communication and engagement activities for use in relation to subsequent projects. Importantly, though, one 
needs to think carefully about the methods used in this research in order to ensure that a representative sample of community stakeholders are questioned and that informed opinions are assessed (e.g., de Best-Waldhober et al., 2009).

\section{Interactions between the Dimensions of Social Acceptance}

Finally, while specific consideration of interactions between the socio-political, market, and community dimensions was beyond the scope of this initial review, it is evidently the case that these three forms of acceptance are often interrelated (Wüstenhagen et al., 2007; Sovacool and Ratan, 2012). As such, a focus of future research should be to develop a better and more comprehensive understanding the nature of these interactions (and implications of thereof) within the context of $\mathrm{CO}_{2}$ utilisation. For example, one could reflect on how the opinions registered by local stakeholders at the community level (e.g., local authorities, affected publics) might serve to affect more general socio-political level acceptance (e.g., national government) decision making (or vice versa). Similarly, one might investigate how general socio-political acceptance might translate into consumer uptake or rejection of specific $\mathrm{CO}_{2}$-derived products.

\section{CONCLUSION}

Research into the social acceptance of the $\mathrm{CO}_{2}$ utilisation is currently at an embryonic stage (the first article was published in 2014); however, perceptions of $\mathrm{CO}_{2}$ utilisation among diverse social stakeholders (e.g., investors, policy-makers, the public) will fundamentally shape the path of $\mathrm{CO}_{2}$ utilisation technologies and $\mathrm{CO}_{2}$-derived projects. The aim of the current article was to outline the importance of considering the "social acceptance" of $\mathrm{CO}_{2}$ utilisation technologies and products, while simultaneously identifying some of the key factors and actors likely to shape this acceptance. We utilised the "triangle of social acceptance" (Wüstenhagen et al., 2007) as a framework for structuring the

\section{REFERENCES}

Alänge, S., Jacobsson, S., and Jaryehammar, A. (1998). Some aspects of an analytical framework for studying the diffusion of organizational innovations. Technol. Anal. Strateg. Manag. 10, 3-22. doi:10.1080/09537329808524301

Aragón-Correa, J. A., and Sharma, S. (2003). A contingent resource-based view of proactive corporate environmental strategy. Acad. Manag. Rev. 28, 71-88. doi:10.5465/AMR.2003.8925233

Arning, K., Van Heek, J., and Ziefle, M. (2017). Risk perception and acceptance of CDU consumer products in Germany. Paper Presented at the 13th International Conference on Greenhouse Gas Control Technologies (GHGT-13), Lausanne, Switzerland.

Batel, S., Devine-Wright, P., and Tangeland, T. (2013). Social acceptance of low carbon energy and associated infrastructures: a critical discussion. Energy Policy 58, 1-5. doi:10.1016/j.enpol.2013.03.018

Beierle, T. C., and Cayford, J. (2002). Democracy in Practice: Public Participation in Environmental Decisions. Washington, DC: Resources for the Future.

Bell, D., Gray, T., and Haggett, C. (2005). The 'social gap' in wind farm siting decisions: explanations and policy responses. Env. Polit. 14, 460-477. doi:10.1080/09644010500175833

Bell, D., Gray, T., Haggett, C., and Swaffield, J. (2013). Re-visiting the 'social gap': public opinion and relations of power in the local politics of wind energy. Env. Polit. 22, 115-135. doi:10.1080/09644016.2013.755793 article in order to help "carve up" this complex and multi-faceted concept into more digestible pieces. Crucially, this review was not designed to be an exhaustive precis and synthesis of all of the specific stakeholders and issues that should be considered in this arena, but was rather designed to elucidate the most important players and considerations that should be kept in mind when seeking to broach the subject of social acceptance in the context of $\mathrm{CO}_{2}$ utilisation.

It is intended that this review and research agenda should form the basis for increased collaborative research between social scientists, pure scientists and engineers around $\mathrm{CO}_{2}$ utilisation technologies and products; such that development and deployment decisions appropriately recognise and respond to the social context for their introduction (e.g., Jones and Jones, 2016).

\section{AUTHOR CONTRIBUTIONS}

All named authors have contributed to all aspects of the writing process, including the initial conception of the review and the drafting and revision of the article. All authors approved the final the version of the article and agreed to be accountable for what it contains.

\section{ACKNOWLEDGMENTS}

The authors would like to thank Prof. Peter Styring (CDUUK/ University of Sheffield) for his helpful advice in preparing this article. We would also like to thank $\mathrm{CO} 2 \mathrm{Chem}$ and $\mathrm{CO}_{2} \mathrm{Plus}$ for bringing the authors together to write this article. All appropriate permissions have been obtained from the copyright holders for any work that has been reproduced in this manuscript.

\section{FUNDING}

This article is part-funded under EPSRC CO2Chem grant EP/ K007947/1 and EPSRC LifesCO2R grant EP/N009746/1.

Bennett, S. J., Schroeder, D. J., and McCoy, S. T. (2014). Towards a framework for discussing and assessing $\mathrm{CO}_{2}$ utilisation in a climate context. Energy Procedia 63, 7976-7992. doi:10.1016/j.egypro.2014.11.835

Bouffard, F., and Kirschen, D. S. (2008). Centralised and distributed electricity systems. Energy Policy 36, 4504-4508. doi:10.1016/j.enpol.2008.09.060

Bringezu, S. (2014). Carbon recycling for renewable materials and energy supply: recent trends, long-term options, and challenges for research and development. J. Ind. Ecol. 18, 327-340. doi:10.1111/jiec.12099

Bruhn, T., Naims, H., and Olfe-Kräutlein, B. (2016). Separating the debate on $\mathrm{CO}_{2}$ utilisation from carbon capture and storage. Environ. Sci. Policy 60, 38-43. doi:10.1016/j.envsci.2016.03.001

Brunsting, S., Upham, P., Dütschke, E., de Best Waldhober, M., Oltra, C., Desbarats, J., et al. (2011). Communicating CCS: applying communications theory to public perceptions of carbon capture and storage. Int. J. Greenhouse Gas Control 5, 1651-1662. doi:10.1016/j.ijggc.2011.09.012

Chong, D., and Druckman, J. N. (2007). Framing theory. Annu. Rev. Political Sci. 10, 103-126. doi:10.1146/annurev.polisci.10.072805.103054

de Best-Waldhober, M., Daamen, D., and Faaij, A. (2009). Informed and uninformed public opinions on $\mathrm{CO}_{2}$ capture and storage technologies in the Netherlands. Int. J. Greenhouse Gas Control 3, 322-332. doi:10.1016/j.ijggc.2008.09.001

de Vries, G., Terwel, B. W., and Ellemers, N. (2016). Perceptions of manipulation and judgments of illegitimacy: pitfalls in the use of emphasis framing when 
communicating about $\mathrm{CO}_{2}$ capture and storage. Environ. Commun. 10, 206-226. doi:10.1080/17524032.2015.1047884

Devine-Wright, P. (ed.) (2011). Renewable Energy and the Public: From NIMBY to Participation. Abingdon, UK: Routledge.

Dobson, A. (1998). Justice and the Environment: Conceptions of Environmental Sustainability and Theories of Distributive Justice. Gloucestershire, UK: Clarendon Press.

Druckman, J. N., and Bolsen, T. (2011). Framing, motivated reasoning, and opinions about emergent technologies. J. Commun. 61,659-688. doi:10.1111/j.1460-2466. 2011.01562.x

Fournis, Y., and Fortin, M. J. (2017). From social 'acceptance' to social 'acceptability' of wind energy projects: towards a territorial perspective. J. Environ. Plann. Manag. 60, 1-21. doi:10.1080/09640568.2015.1133406

Freeman, R.E. (2004). The stakeholder approach revisited.Z. Wirtsch. Unternehmen. $5,228-241$.

Freeman, R. E. (2010). Strategic Management: A Stakeholder Approach. Cambridge: Cambridge University Press. doi:10.1017/CBO9781139192675

Gupta, N., Fischer, A. R., and Frewer, L. J. (2012). Socio-psychological determinants of public acceptance of technologies: a review. Public Underst. Sci. 21, 782-795. doi:10.1177/0963662510392485

Hampel, J., and Zwick, M. (2016). Wahrnehmung, Bewertung und die Akzeptabilität von Technik in Deutschland. Tech. Theorie Prax. 25, 24-38.

Hauke, N. (2014). "Die grüne Revolution an der Tankstelle? Die Relevanz politischer Narrative am Beispiel der Einführung des Biokraftstoffes E10," in Politische Narrative, eds F. Gadinger, S. Jarzebski, and T. Yildiz (Wiesbaden, Germany: Springer), 173-197.

Hemmati, M. (2002). Multi-Stakeholder Processes for Governance and Sustainability: Beyond Deadlock and Conflict. Abingdon, UK: Routledge.

Horlick-Jones, T., Walls, J., Rowe, G., Pidgeon, N., Poortinga, W., and O'Riordan, T. (2006). On evaluating the GM Nation? Public debate about the commercialisation of transgenic crops in Britain. New Genet. Soc. 25, 265-288. doi:10.1080/14636770601032858

Huijts, N. M., Molin, E. J., and Steg, L. (2012). Psychological factors influencing sustainable energy technology acceptance: a review-based comprehensive framework. Renew. Sustain. Energ. Rev. 16, 525-531. doi:10.1016/j.rser.2011.08.018

Intergovernmental Panel on Climate Change. (2005). "IPCC carbon dioxide capture and storage," in Prepared by Working Group III of the Intergovernmental Panel on Climate Change, eds B. Metz, O. Davidson, H. C. de Coninck, M. Loos, and L. A. Meyer (Cambridge, NY: Cambridge University Press).

Jones, C. R., and Eiser, J. R. (2010). Understanding 'local' opposition to wind development in the UK: how big is a backyard? Energy Policy 38, 3106-3117. doi:10.1016/j.enpol.2010.01.051

Jones, C. R., Eiser, J. R., and Gamble, T. R. (2012). Assessing the impact of framing on the comparative favourability of nuclear power as an electricity generating option in the UK. Energy Policy 41, 451-465. doi:10.1016/j.enpol.2011.11.006

Jones, C. R., and Jones, A. R. (2016). Two blind mice: it is time for greater collaboration between engineers and social scientists around the RDD \& D of industrial technologies. C J. Carbon Res. 2, 16. doi:10.3390/c2020016

Jones, C. R., Kaklamanou, D., Stuttard, W. M., Radford, R. L., and Burley, J. (2015). Investigating public perceptions of carbon dioxide utilisation (CDU) technology: a mixed methods study. Faraday Discuss. 183, 327-347. doi:10.1039/ C5FD00063G

Jones, C. R., Olfe-Kräutlein, B., and Kaklamanou, D. (2016). Lay perceptions of carbon dioxide capture and utilisation technologies in the UK and Germany: a qualitative interview study. Paper Presented at the $14^{\text {th }}$ International Conference on Carbon Dioxide Utilisation (ICCDU), Sheffield, UK.

Jones, C. R., Orr, B. J., and Eiser, J. R. (2011). When is enough, enough? Identifying predictors of capacity estimates for onshore wind-power development in a region of the UK. Energy Policy 39, 4563-4577. doi:10.1016/j.enpol.2011.04.044

Jones, C. R., Radford, R. L., Armstrong, K., and Styring, P. (2014). What a waste! Assessing public perceptions of carbon dioxide utilisation technology. J. $\mathrm{CO}_{2}$ Util. 7, 51-54. doi:10.1016/j.jcou.2014.05.001

Kepplinger, H. M. (2007). Reciprocal effects: toward a theory of mass media effects on decision makers. Harv. Int. J. Press/Polit. 12, 3-23. doi:10.1177/108 1180 X07299798

Krämer, D., Roth, S., and Wunder, C. (2015). Vom Abfall zum Rohstoff: Kann $\mathrm{CO}_{2}$ in Zukunft Erdöl ersetzen? Available at: https://www.bmbf.de/pub/ Vom_Abfall_zum_Rohstoff.pdf
L'Orange Seigo, S., Dohle, S., and Siegrist, M. (2014). Public perception of carbon capture and storage (CCS): a review. Renew. Sustain. Energ. Rev. 38, 848-863. doi:10.1016/j.rser.2014.07.017

Manzo, L. C., and Perkins, D. D. (2006). Finding common ground: the importance of place attachment to community participation and planning. J. Plann. Lit. 20, 335-350. doi:10.1177/0885412205286160

Montijn-Dorgelo, F. N., and Midden, C. J. (2008). The role of negative associations and trust in risk perception of new hydrogen systems. J. Risk Res 11, 659-671. doi:10.1080/13669870801967218

Naims, H. (2016). Economics of carbon dioxide capture and utilization - a supply and demand perspective. Environ. Sci. Pollut. Res. 23, 22226-22241. doi:10.1007/s11356-016-6810-2

Olfe-Kräutlein, B., Naims, H., Bruhn, T., and Lorente Lafuente, A. M. (2016). $\mathrm{CO}_{2}$ as an Asset - Challenges and Potential for Society. Potsdam, Germany: IASS.

Olfe-Kräutlein, B., Naims, H., Bruhn, T., Lorente Lafuente, A. M., and Tobias, M. (2014). $\mathrm{CO}_{2}$ as an Asset? IASS Fact Sheet, 2/2014. Potsdam, Germany: IASS. Available at: http://www.iass-potsdam.de/sites/default/files/files/fact_sheet_ en_2_2014.pdf

Oltra, C., Upham, P., Riesch, H., Boso, À., Brunsting, S., Dütschke, E., et al. (2012). Public responses to $\mathrm{CO} 2$ storage sites: lessons from five European cases. Energy Environ. 23, 227-248. doi:10.1260/0958-305X.23.2-3.227

Ottinger, G. (2013). Changing knowledge, local knowledge, and knowledge gaps: STS insights into procedural justice. Sci. Technol. Hum. Values 38, 250-270. doi:10.1177/0162243912469669

Perdan, S., Jones, C. R., and Azapagic, A. (2017). Public awareness and acceptance of carbon capture and utilisation in the UK. Sustainable Prod. Consumption 10, 74-84. doi:10.1016/j.spc.2017.01.001

Perlaviciute, G., and Steg, L. (2014). Contextual and psychological factors shaping evaluations and acceptability of energy alternatives: integrated review and research agenda. Renew. Sustain. Energ. Rev. 35, 361-381. doi:10.1016/j. rser.2014.04.003

Peterson, T. R., Stephens, J. C., and Wilson, E. J. (2015). Public perception of and engagement with emerging low-carbon energy technologies: a literature review. MRS Energy Sustainability 2, E11. doi:10.1557/mre.2015.12

Pietzner, K., Schumann, D., Tvedt, S. D., Torvatn, H. Y., Naess, R., Reiner, D. M., et al. (2011). Public awareness and perceptions of carbon dioxide capture and storage (CCS): insights from surveys administered to representative samples in six European countries. Energy Procedia 4, 6300-6306. doi:10.1016/j. egypro.2011.02.645

Piria, R., Naims, H., and Lorente Lafuente, A. M. (2016). Carbon Capture and Utilisation (CCU): Klimapolitische Einordnung und innovationspolitische Bewertung. Available at: https://www.adelphi.de/en/publications

Rogers, E. M. (1995). Diffusion of Innovations. New York: The Free Press.

Roloff, J. (2008). Learning from multi-stakeholder networks: issue-focussed stakeholder management. J. Bus. Ethics 82, 233-250. doi:10.1007/s10551-007-9573-3

Schively, C. (2007). Understanding the NIMBY and LULU phenomena: reassessing our knowledge base and informing future research. J. Plann. Lit. 21, 255-266. doi:10.1177/0885412206295845

Shove, E. (2010). Beyond the ABC: climate change policy and theories of social change. Environ. Plann. A 42, 1273-1285. doi:10.1068/a42282

Sovacool, B. K., and Ratan, P. L. (2012). Conceptualizing the acceptance of wind and solar electricity. Renew. Sustain. Energ. Rev. 16, 5268-5279. doi:10.1016/j. rser.2012.04.048

Styring, P., Jansen, D., de Coninck, H., Reith, H., and Armstrong, K. (2011). Carbon Capture and Utilization in the Green Economy. Available at: http://co2chem. co.uk/wp-content/uploads/2012/06/CCU\%20in\%20the\%20green\%20economy\%20report.pdf

Styring, P., Quadrelli, E. A., and Armstrong, K. (eds) (2014). Carbon Dioxide Utilisation: Closing the Carbon Cycle. Amsterdam: Elsevier.

Szarka, J. (2007). Wind Power in Europe: Politics, Business and Society: Energy, Climate, and the Environment Series. Houndmills: Palgrave Macmillan.

Terwel, B. W., Harinck, F., Ellemers, N., and Daamen, D. D. L. (2011). Going beyond the properties of $\mathrm{CO}_{2}$ capture and storage (CCS) technology: how trust in stakeholders affects public acceptance of CCS. Int. J. Greenhouse Gas Control 5, 181-188. doi:10.1016/j.ijggc.2010.10.001

Toke, D., Breukers, S., and Wolsink, M. (2008). Wind power deployment outcomes: how can we account for the differences? Renew. Sustain. Energ. Rev. 12, 1129-1147. doi:10.1016/j.rser.2006.10.021 
Upham, P., Oltra, C., and Boso, À (2015). Towards a cross-paradigmatic framework of the social acceptance of energy systems. Energy Res. Soc. Sci. 8, 100-112. doi:10.1016/j.erss.2015.05.003

van der Horst, D. (2007). NIMBY or not? Exploring the relevance of location and the politics of voiced opinions in renewable energy siting controversies. Energy Policy 35, 2705-2714. doi:10.1016/j.enpol.2006.12.012

Van Der Pligt, J., Eiser, J. R., and Spears, R. (1986). Attitudes toward nuclear energy: familiarity and salience. Environ. Behav. 18, 75-93. doi:10.1177/0013916586181004

van Heek, J., Arning, K., and Ziefle, M. (2017a). Differences between laypersons and experts in perceptions and acceptance of $\mathrm{CO}_{2}$-utilization for plastic products. Paper Presented at the 13th International Conference on Greenhouse Gas Control Technologies (GHGT-13), Lausanne, Switzerland.

van Heek, J., Arning, K., and Ziefle, M. (2017b). Reduce, reuse, recycle: acceptance of $\mathrm{CO}_{2}$-utilization for plastic products. Energy Policy 105, 53-66. doi:10.1016/j. enpol.2017.02.016

Venkatesh, V., and Davis, F. D. (2000). A theoretical extension of the technology acceptance model: four longitudinal field studies. Manage. Sci. 46, 186-204. doi:10.1287/mnsc.46.2.186.11926

von der Assen, N., and Bardow, A. (2014). Life cycle assessment of polyols for polyurethane production using $\mathrm{CO}_{2}$ as feedstock: insights from an industrial case study. Green Chem. 16, 3272-3280. doi:10.1039/c4gc00513a

von der Assen, N., Müller, L. J., Steingrube, A., Voll, P., and Bardow, A. (2016). Selecting $\mathrm{CO}_{2}$ sources for $\mathrm{CO}_{2}$ utilization by environmental-merit-order curves. Environ. Sci. Technol. 50, 1093-1101. doi:10.1021/acs.est.5b03474

Walker, G., and Devine-Wright, P. (2008). Community renewable energy: what should it mean? Energy Policy 36, 497-500. doi:10.1016/j.enpol.2007.10.019

Weitze, M.-D., and Weingart, P. (2016). Schlüsselideen, Akteure und Formate der Technikkommunikation. Tech. Theorie Prax. 25, 4-7.
Wilson, G., Travaly, Y., Brun, T., Knippels, H., Armstrong, K., Styring, P., et al. (2015). A Vision for Smart $\mathrm{CO}_{2}$ Transformation in Europe: Using $\mathrm{CO}_{2}$ as a Resource. SCOT Project. Available at: http://www.scotproject.org/images/ SCOT\%20Vision.pdf

Wolsink, M. (2010). Contested environmental policy infrastructure: socio-political acceptance of renewable energy, water, and waste facilities. Environ. Impact Assess. Rev. 30, 302-311. doi:10.1016/j.eiar.2010.01.001

Wolsink, M. (2012). The research agenda on social acceptance of distributed generation in smart grids: renewable as common pool resources. Renew. Sustain. Energ. Rev. 16, 822-835. doi:10.1016/j.rser.2011.09.006

Wüstenhagen, R., Wolsink, M., and Bürer, M. J. (2007). Social acceptance of renewable energy innovation: an introduction to the concept. Energy Policy 35, 2683-2691. doi:10.1016/j.enpol.2006.12.001

Young, I. M. (1986). The ideal of community and the politics of difference. Soc. Theory Pract. 12, 1-26. doi:10.5840/soctheorpract198612113

Zimmerman, A., and Kant, M. (2016). The Business Side of Innovative $\mathrm{CO}_{2}$ Utilisation. Berlin: EIT Climate KIC/TU Berlin. Available at: http://enco2re.climate-kic.org/wp-content/uploads/2016/01/The-business-side-of-innovativeCO2-utilisation.pdf

Conflict of Interest Statement: The authors did not at any time receive payment or services from a third party for any aspect of the submitted work.

Copyright (C) 2017 Jones, Olfe-Kräutlein, Naims and Armstrong. This is an open-access article distributed under the terms of the Creative Commons Attribution License (CC BY). The use, distribution or reproduction in other forums is permitted, provided the original author(s) or licensor are credited and that the original publication in this journal is cited, in accordance with accepted academic practice. No use, distribution or reproduction is permitted which does not comply with these terms. 